\title{
Psychotherapeutic intervention on breast self-examination based on Health Belief Model
}

\author{
Adelina Mihaela Ştefănuț ${ }^{1} \cdot$ Mona Vintilă ${ }^{1}$
}

Accepted: 2 February 2022

(c) The Author(s), under exclusive licence to Springer Science+Business Media, LLC, part of Springer Nature 2022

\begin{abstract}
The aim of this research was to verify the effectiveness of a Health Belief Model-based intervention in increasing knowledge and changing beliefs about breast cancer and its early detection as well as in improving breast self-examination behaviors. This randomized controlled clinical trial involved 210 women. The program was implemented by email and involved sending daily messages to participants for 30 days. The women in the intervention group received messages aimed at increasing the practice of breast self-examination behavior. Participants in the control group received messages promoting general health. Before and after the intervention there were evaluated the application of breast self-examination, level of knowledge, beliefs associated with health (susceptibility to develop breast cancer, disease severity, benefits of self-examination, barriers to achieving this behavior, cues to action, self-efficacy in performing self-examination). At the end of the program, a significant improvement in the perception of disease severity and the benefits of breast self-examination was obtained, as well as a significant increase in the percentage of participants who achieved this behavior. The results obtained are arguments for it to be implemented by health care providers who want to promote self-examination as a method of early detection of breast cancer.
\end{abstract}

Keywords Breast cancer prevention $\cdot$ Breast self-examination $\cdot$ Beliefs $\cdot$ Health Belief Model $\cdot$ Intervention

\section{Introduction}

Cancer is a serious disease that continues to spread and has a significant physical, emotional and financial burden on affected individuals and their families as well as on the community and health systems. Globally, this disease was the second leading cause of death in 2018, accounting for one in six deaths (World Health Organization, 2021a). A quarter of these occur in low- and middle-income countries where the necessary medical resources are not available (American Cancer Society, 2021). Of the various types of cancer, breast cancer was the second most common in 2018 (2.09 million cases), being responsible for the deaths of 627,000 women in that year alone (World Health Organization, 2021a). It has also been found that globally there is a significant increase in this type of cancer (Heer et al., 2020), the American Cancer Society estimates for example that in the US the incidence of

Mona Vintilă

mona.vintila@e-uvt.ro

1 Department of Psychology, West University of Timişoara, Vasile Pârvan Blvd., 300223 Timișoara, Romania breast cancer increased annually by $0.5 \%$ per year between 2008 and 2017 (American Cancer Society, 2021).

In this context, prevention and early detection are important means of reducing the burden of this disease (World Health Organization, 2021b). Prevention of breast cancer includes lifestyle changes, avoidance of risk factors, medication to treat precancerous conditions, and risk reduction surgery (National Cancer Institute, 2021). Increasing breast awareness in the Western society offers better prognosis for early detection of breast cancer (Swami et al., 2020). The disease does not impact only the patient, but also the partner, affecting their life-style and the levels of anxiety, depression and distress increases significantly (Vintilă et al., 2019), coping with the disease will involve both partners (Ștefănuț et al., 2020), as such including the partner in addressing the topic of early detection of breast cancer becomes of interest. Common dyadic coping has proven to be an important part of the quality of relationship in these particular situation (Ștefănuț et al., 2020).

For early detection, the World Health Organization (2021c) recommends mammography but notes that this is an expensive screening method, not applicable in countries with limited medical resources, so other screening methods 
must be considered. Such ways of screening for breast cancer are clinical examination of the breasts as well as selfexamination. Although there have been disputes about the usefulness of breast self-examination as a unique screening method in reducing breast cancer mortality (Thomas et al., 2002), this behavior is still recommended for early detection of the disease (Crossing \& Manaszewicz, 2003). Along with education, it is also a way to improve breast health awareness as well as a way to increase adherence to clinical examination and mammography (Anderson \& Jakesz, 2008; Anderson et al., 2003).

Breast self-examination requires women to know what their healthy breasts look and feel like in order to check for any nodules, secretions, and changes in size, shape, texture, color (National Breast Cancer Foundation, 2021). This is a low-cost, non-invasive method that requires little time to apply and can be done even by women at home. Despite all these advantages, the frequency of application is variable 44.4\%-75\% (Dewi et al., 2019; Tu et al., 2006; van Dooren et al., 2003), and the quality of the examination is low, the percentage of those who perform correctly procedure ranging from $15.7 \%$ to $27 \%$ (Carelli et al., 2008; Tu et al., 2006). According to various studies, factors influencing breast self-examination include: beliefs and attitudes about breast cancer, knowledge about risk factors, social influence, selfefficacy (Luszczynska \& Schwarzer, 2003; Lechner et al., 2004; Mason \& White, 2008; Didarloo et al., 2017; Dewi et al., 2019; Ju et al., 2021).

Along with the identification of the factors involved in the adoption of the self-examination behavior of the breasts, there were also interventions that aimed to increase its frequency. One of the most widely used theoretical frameworks for defining these interventions is the Health Belief Model (HBM) (Rosenstock, 1974). This model was originally proposed in an attempt to understand the low adherence to tuberculosis screening and prevention programs, but was later used in other diseases such as cancer. The constructs included in the model are: the perception of the susceptibility to develop the disease, the perception of the severity of its consequences, the benefits perceived as a result of the application of prevention and early detection behaviors, the perceived barriers to achieving those behaviors, the perceived self-efficacy action, namely those internal or external triggers that contribute to the decision to adopt behaviors. According to the model, a person is more likely to perform breast self-examination if she perceives that there is a high chance of developing breast cancer, if she considers that the consequences of the disease are serious and self-examination leads to their reduction. It is also more likely that someone will perform self-examination of the breasts as they consider that they are able to perform this behavior and the obstacles to achieving it are less. In addition, the existence of cues to action is likely to favor the realization of self-examination.
HBM-based interventions have achieved significant positive results in modifying HBM constructs, improving knowledge, and increasing the frequency of breast selfexamination (Akhtari-Zavare et al., 2016; Tuzcu et al., 2016; Secginli \& Nahcivan, 2011; Hajian et al., 2011). They were developed face-to-face and included information on breast anatomy, the incidence, consequences and symptoms of breast cancer, and screening methods. Printed educational materials, reminder cards were used and some interventions included the practice of examining the breast using silicone models.

According to the data available on the WHO website (World Health Organization, 2021d) in Romania, breast cancer has an incidence of $11.5 \%$ and a mortality of $6.6 \%$. It ranks first in cancer deaths among Romanian women (Furtunescu et al., 2021). Regarding the early detection of this disease, so far, despite pilot programs and attempts to include mammography in national health programs, there is no nationally organized screening program. Access to mammography is fragmented and often involves payment (Furtunescu et al., 2021). In this context, educating women about breast cancer, the possibilities of prevention and early detection and especially the detection by inexpensive methods is a priority.

The present study aims to define and evaluate the effectiveness of an intervention based on HBM in terms of changing beliefs about breast cancer and its prevention, improving knowledge about them and increasing the frequency of breast self-examination. Given the specific situation created by the COVID-19 pandemic that required compliance with physical distance, the research used email as a way to deliver content. The specific hypotheses formulated are:

H1: after the end of the program there will be a statistically significant increase in the level of knowledge regarding breast cancer and its early detection in the intervention group compared to the control group;

$\mathrm{H} 2$ : after the end of the program there will be a statistically significant increase in the perception of susceptibility, severity, benefits, self-efficacy and cues to action and a significant decrease in the perception of barriers in the intervention group compared to the control group;

H3: after the completion of the program there will be a statistically significant increase in the percentage of women who perform breast self-examination in the intervention group compared to the control group.

The novelty elements brought by this study include the method of carrying out the intervention whose informational content is transmitted by email as well as the fact that the Romanian population is targeted, little studied from this point of view. The use of email presents compared to the interventions carried out face to face the advantage of a low 
cost and of a high accessibility, not restricted by the geographical location of the targeted participants.

\section{Methods}

\section{Study Design}

For this study, an experimental design with randomized distribution of participants in the intervention group and in the control group was used. There were two evaluations of the participants: before the intervention and two weeks after its completion. After performing the first evaluation, a researcher independent to this study performed the random allocation of participants in the intervention group and in the control group by using the program. www.random.org/ sequences.

\section{Participants}

The study was addressed to the students at the Faculty of Sociology and Psychology. The inclusion criteria in the study were the following: a) female gender; b) minimum age of 18 years; c) knowledge of the Romanian language; d) internet access; e) access to an email account. Considering a $20 \%$ increase in breast self-examination behavior, a statistical power of $80 \%$ and a level of statistical significance of 0.05 , it was calculated that in each of the two groups a number of 93 women is required. Taking into account a dropout rate of $20 \%$, the objective was to recruit 232 participants. Following the announcement made by the researchers in the study, a number of 238 women registered and completed the initial questionnaires, 120 of them being randomly distributed in the intervention group and 119 in the control group. During the intervention, 29 women abandoned the study so that 210 participants responded to the final evaluation, 107 from the intervention group and 103 from the control group (Fig. 1).

\section{Procedure}

The research took place between April and May 2021 at the West University of Timișoara whose Ethics Commission expressed its agreement for the development. Students from the Faculty of Sociology and Psychology were informed about the possibility to participate in this study (in the case of women) or to invite other interested persons to participate (in the case of boys). Interested persons received access to an online form. Following informed consent, they were assessed online for beliefs and knowledge about breast cancer and its early detection, as well as the frequency of breast self-examination. After this first evaluation, participants were randomly assigned to either the intervention group or

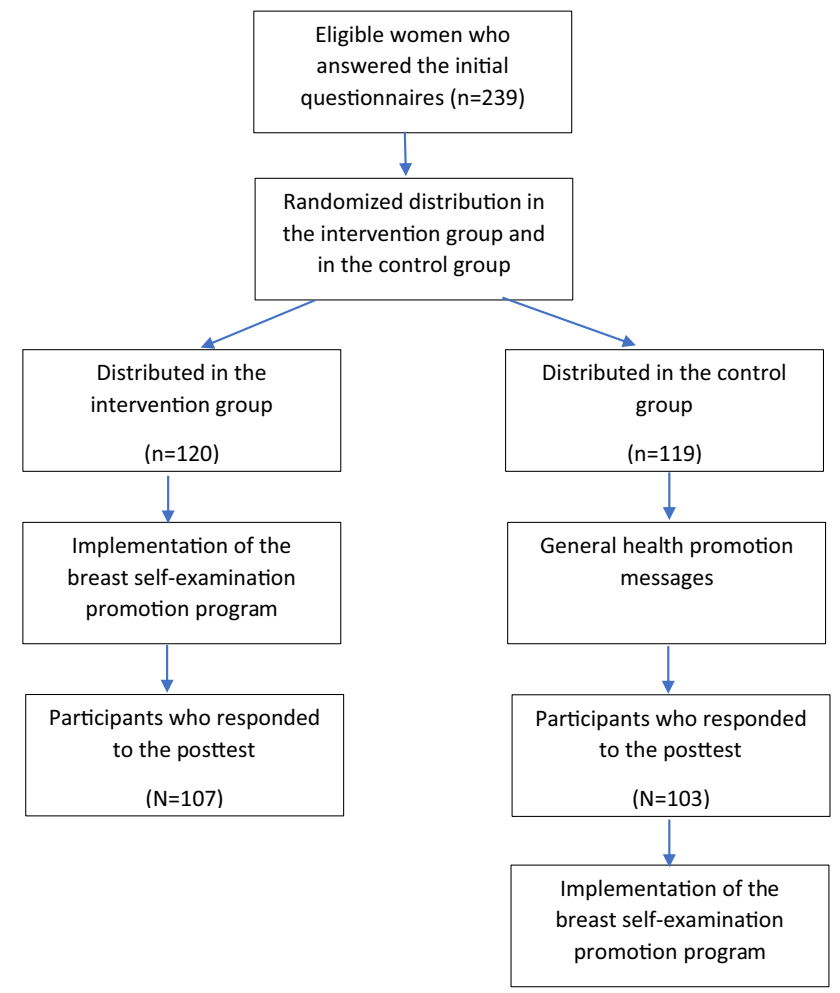

Fig. 1 Flow diagram of study participants

the control group. The result of the randomization was not made known to the participants. For 30 days all participants received daily emails containing messages of the program. People in the intervention group received messages aimed at changing beliefs and improving breast self-examination knowledge and behaviors, while people in the control group received general health promotion messages. Two weeks after the end of the intervention, a new online assessment of the participants' beliefs and knowledge regarding breast cancer and its early detection as well as self-examination of the breasts took place. After this evaluation, the control group also received specific messages intended to promote breast self-examination.

\section{Variables and Instruments}

Before and at the end of the intervention, the following variables were measured: beliefs about breast cancer and self-examination behavior (susceptibility, severity, benefits, barriers, self-efficacy, action indices), level of knowledge and frequency of self- examinations.

Demographic data collected included age, social status (alone / in a relationship), living environment (urban / rural), general health (poor / good / very good), last school completed, occupational status, family history of cancer (no 
history of family cancer / with a history of breast cancer in the family / with a history of cancer other than breast cancer).

HBM beliefs were evaluated using Champion Health Belief Model Scale, translated and validated on the Romanian population (Ștefănuț \& Vintilă, 2021). This questionnaire contains 34 items distributed in six subscales: perceived susceptibility (4 items), perceived severity (9 items), perceived benefits ( 5 items), perceived barriers ( 7 items), cues to action ( 7 items) and self-efficacy perceived ( 2 items). A 5-point Likert scale was used for answers $(1=$ strong disagreement; $5=$ strong agreement). The total score for each scale was obtained by summing the points obtained for each of the items included in that scale. Higher values reflected higher levels of assessed beliefs. For this sample the Cronbach's $\alpha$ coefficients varied between 0.77 (susceptibility and benefit scales) and 0.85 (barrier scale).

Knowledge about breast cancer and its early detection was assessed through a questionnaire that included 15 items on general knowledge about risk factors, symptoms and ways to detect the disease early. The answers to the items were true-false. Each correct answer was scored with 1 and each wrong answer with 0 . The total score was obtained by summing these points. A higher overall score was associated with a higher level of knowledge. This tool was developed specifically for the present research, was based on a review of the existing literature and was pre-tested on a sample of 15 women who were not included in the present study.

Breast self-examination was assessed using two questions. A question about the frequency of breast self-examination and whose possible answers were: once a month / occasionally / never and a question about whether self-examination was performed last month with possible answers: yes / no.

\section{Breast Self-Examination Promotion Program}

The participants in the intervention group received for 30 days, an email containing information on breast cancer, early detection methods and how to perform self-examination. According to HBM, a person is more likely to perform breast self-examination if they think they are more likely to develop breast cancer, if the perceived consequences of the disease are more severe, if the benefits of achieving this behavior outweigh the possible obstacles to its adoption, if it is believed to be able to put it into practice if there are environmental elements that encourage this action. The structure of the messages included in the program was consistent with the structure used by Aquino et al. (2020) in the neuroscience of persuasion, which used five arguments to obtain a change of attitude. Thus, in our intervention, five emails were aimed at increasing the perception of susceptibility, five aimed at increasing severity and another five aimed at increasing benefits. Also, five emails aimed at reducing perceived barriers, eight messages aimed at improving selfefficacy and two indices of action.

The messages aimed at increasing the perception of the susceptibility to develop the disease included information about the degree of its spread among the female population but also information about what may constitute an increased individual risk (example: "The existence of a family history of breast or ovarian cancer increases the risk of breast cancer."). The messages also highlighted the severity of the consequences of the disease for both the diagnosed person and his family members (example: "A diagnosis of breast cancer can seriously affect the well-being and the activities of all family members."). In addition, the advantages of this specific method of early detection of the disease were presented, as well as the way in which the negative consequences of the disease can be reduced (example: "Regular self-examination of the breasts can help detect nodules in the time interval between clinical routine examinations."). The program aimed to reduce the perception of barriers such as lack of information, negative emotions that may accompany the application of self-examination behavior (fear of discovering a lump), but also the difficulty of regularly performing this behavior (example: "There is no medical risk involved in a breast self-examination. Finding a lump in your breast can be alarming, but most breast lumps are not cancerous. They are typically caused by other benign conditions."). The messages aimed at increasing self-efficacy briefly described the steps to follow for self-examination as well as the recommendation of what should be done in case of abnormalities (example: "The first step of breast self-examination. Selfexamination of the breasts begins with sitting bare-chested in front of the mirror, with straight shoulders and palms at the hips. Any change in the size, shape or color of the breasts is observed."). Action indices included messages that could contribute to the decision to self-examine either by observing and meditating on external events or by raising awareness on internal states (example: "Observing breast cancer among the known persons could be a serious reason to meditate on methods for early detection of the disease.").

The participants in the control group received for 30 days an email containing general information regarding health risk behaviors as well as behaviors that favor it. Examples: "The consumption of alcoholic beverages is a routine for social activities in the case of many populations, but its limitation is beneficial to health."

The content of all these messages was defined prior to the intervention and described in the intervention protocol.

\section{Statistical Analysis}

Data were analyzed using SPSS version 20. Descriptive statistics were used to analyze the distribution of demographic characteristics in both the intervention group and the control 
group. Chi-square analyzes and independent $t$-tests were applied to assess the differences between the intervention group and the control group. Paired- $t$ tests were applied to measure changes in health knowledge and beliefs in the preand post-intervention intervention group and binomial tests were used to measure changes in self-examination behavior in the pre- and post-intervention group.

\section{Results}

\section{Demographic Characteristics}

The study enrolled 239 women, of whom 210 completed the program, 107 in the intervention group and 103 in the control group. The average age of the participants was 23.66 years $(\mathrm{SD}=8.52)$. Most participants were involved in a relationship (60.5\%), completed high school $(68.9 \%)$, live in urban areas $(74.8 \%)$, are students $(77.7 \%)$ who have a good level of health $(51.7 \%)$ and don't have a family history of cancer $(55 \%)$. The tests performed showed that there were no significant differences between the intervention group and the control group in terms of demographic characteristics (Table 1).

\section{Sample Attrition}

Figure 1 illustrates the situation of the program participants. The dropout rate was of $12.13 \%$ and there were no statistically significant differences between the characteristics of participants who completed the program and those who did not complete it. There were also no significant differences between the characteristics of participants who did

Table 1 Demographic characteristics of participants

\begin{tabular}{|c|c|c|c|c|}
\hline Demographics & $\begin{array}{l}\text { All participants }(N=238) \\
\text { Number }(\%)\end{array}$ & $\begin{array}{l}\text { Intervention group }(N=120) \\
\text { Number }(\%)\end{array}$ & $\begin{array}{l}\text { Control group } \\
(N=118) \\
\text { Number }(\%)\end{array}$ & Statistics \\
\hline Age & $\mathrm{M}=23.66(\mathrm{SD}=8.52)$ & $\mathrm{M}=23.93(\mathrm{SD}=9.44)$ & $\mathrm{M}=23.37(\mathrm{SD}=7.51)$ & $\mathrm{t}(236)=0.5 ; p=0.61$ \\
\hline \multicolumn{5}{|l|}{ Relationship status } \\
\hline Single & $94(39.5)$ & $49(40.8)$ & $45(38.1)$ & \multirow[t]{2}{*}{$\mathrm{X}^{2}(1)=0.18 ; p=0.67$} \\
\hline In a relationship & $144(60.5 \%)$ & $71(59.2)$ & $73(61.9)$ & \\
\hline \multicolumn{5}{|l|}{ Educational status } \\
\hline Middle school & $4(1.7 \%)$ & $0(0)$ & $4(3.4)$ & \multirow{6}{*}{$\begin{array}{l}\text { Ficher's Exact test }=4.25 \text {; } \\
\quad p=0.35\end{array}$} \\
\hline High school & $164(68.9 \%)$ & $85(70.8)$ & $79(66.9)$ & \\
\hline Vocational school & $0(0 \%)$ & $0(0)$ & $0(0)$ & \\
\hline Bachelor's degree & $49(20.6 \%)$ & $25(20.8)$ & $24(20.3)$ & \\
\hline Master's degree & $19(8 \%)$ & $9(7.7)$ & $10(8.5)$ & \\
\hline Doctorate & $2(0.8 \%)$ & $1(0.8)$ & $1(0.8)$ & \\
\hline \multicolumn{5}{|l|}{ Living environment } \\
\hline Rural & $60(25.2 \%)$ & $31(25.8)$ & $29(24.6)$ & \multirow[t]{2}{*}{$\mathrm{X}^{2}(1)=0.05 ; p=0.82$} \\
\hline Urban & $178(74.8 \%)$ & $89(74.2)$ & $89(75.4)$ & \\
\hline \multicolumn{5}{|l|}{ Occupational status } \\
\hline Student & $185(77.7 \%)$ & $93(77.5)$ & $92(78)$ & \multirow{5}{*}{$\begin{array}{l}\text { Ficher's Exact test }=2.22 \\
\quad p=0.92\end{array}$} \\
\hline Employee & $46(19.3 \%)$ & $22(18.3)$ & $24(20.3)$ & \\
\hline Bussines owner & $5(2.1 \%)$ & $3(2.5)$ & $2(1.7)$ & \\
\hline Unemployed & $1(0.4 \%)$ & $1(0.8)$ & $0(0)$ & \\
\hline Pensioner & $1(0.4 \%)$ & $1(0.8)$ & $0(0)$ & \\
\hline \multicolumn{5}{|l|}{ Health status } \\
\hline Poor health & $3(1.3 \%)$ & $2(1.7)$ & $1(0.8)$ & \multirow{3}{*}{$\begin{array}{l}\text { Ficher's Exact test }=0.44 \\
\quad p=0.96\end{array}$} \\
\hline Good health & $123(51.7 \%)$ & $61(50.8)$ & $62(52.5)$ & \\
\hline Very goog health & $112(47.1 \%)$ & $57(47.5)$ & $55(46.6)$ & \\
\hline \multicolumn{5}{|l|}{ Family history of cancer } \\
\hline No history of cancer & $131(55 \%)$ & $68(56.7)$ & $63(53.4)$ & \multirow[t]{3}{*}{$\mathrm{X}^{2}(2)=0.32 ; p=0.85$} \\
\hline History of breast cancer & $30(12.6 \%)$ & $14(11.7)$ & $16(13.6)$ & \\
\hline $\begin{array}{l}\text { History of other type of } \\
\text { cancer }\end{array}$ & $77(32.4 \%)$ & $38(31.7)$ & $39(33.1)$ & \\
\hline
\end{tabular}

${ }^{*} p<0.05$ 
not complete the program in the intervention group and the control group.

\section{Changes in Knowledge About Breast Cancer and Its Prevention}

The initial evaluation showed that the level of knowledge about breast cancer and its prevention was high both in the intervention group $M=12.48(\mathrm{SD}=1.79)$ and in the control group $M=12.30(\mathrm{SD}=1.53)$, without statistically significant differences $(p=0.42)$. Because at the final evaluation no statistically significant differences were found between the two groups in terms of knowledge level $(p=0.65)$ (Table 2) we can say that the data do not support the first hypothesis of the study.

\section{Changes in Beliefs About Breast Cancer and Breast Self-Examination}

For none of the beliefs regarding disease and prevention were there significant differences between the intervention group and the control group at the time of the pretest. After the completion of the program, statistically significant increases were observed in the intervention group compared to the control group regarding the perceived severity of the disease $(t=2.30 ; p=0.02)$ as well as regarding

Table 2 Changes in the knowledge about the disease and in the beliefs associated with health according to HBM

\begin{tabular}{llll}
\hline Variables & $\begin{array}{l}\text { Interven- } \\
\text { tion group } \\
(N=107) \\
\text { Mean (SD) }\end{array}$ & $\begin{array}{l}\text { Control group } \\
(N=103)\end{array}$ & Statistics \\
& & & \\
\hline Pretest & & & \\
Knowledge & $12.48(1.79)$ & $12.30(1.53)$ & $t=0.80 ; p=0.42$ \\
Susceptibility & $8.42(2.60)$ & $8.33(2.66)$ & $t=0.22 ; p=0.82$ \\
Severity & $26.97(7.15)$ & $26.89(5.46)$ & $t=0.08 ; p=0.92$ \\
Benefits & $14.39(3.45)$ & $14.10(2.91)$ & $t=0.64 ; p=0.51$ \\
Barriers & $16.08(6.14)$ & $15.19(5.00)$ & $t=1.14 ; p=0.25$ \\
Cues to & $22.74(4.87)$ & $22.51(5.28)$ & $t=0.33 ; p=0.74$ \\
$\quad$ action & & & \\
Self-efficacy & $5.12(2.49)$ & $5.34(2.61)$ & $t=0.64 ; p=0.51$ \\
Posttest & & & \\
Knowledge & $12.16(2.01)$ & $12.05(1.53)$ & $t=0.44 ; p=0.65$ \\
Susceptibility & $8.85(2.94)$ & $8.61(2.82)$ & $t=0.59 ; p=0.55$ \\
Severity & $28.14(6.91)$ & $26.02(6.40)$ & $t=2.30 ; p=0.02^{*}$ \\
Benefits & $15.61(3.17)$ & $14.68(2.95)$ & $t=2.19 ; p=0.02^{*}$ \\
Barriers & $15.72(6.31)$ & $14.58(4.53)$ & $t=1.50 ; p=1.13$ \\
Cues to & $23.09(5.21)$ & $23.67(4.06)$ & $t=0.90 ; p=0.36$ \\
$\quad$ action & & & $t=1.00 ; p=0.31$ \\
Self-efficacy & $5.16(2.47)$ & $5.50(2.62)$ & \\
\hline
\end{tabular}

${ }^{*} p<0.05$ the benefits of breast self-examination $(t=2.19 ; p=0.03)$ (Table 2). These results partially support the second research hypothesis.

\section{Changes in Breast Self-Examination Behavior}

The analyzes performed showed that in terms of the practice of breast self-examination in the last month there were statistically significant differences between the intervention group compared to the control group at the time of the initial evaluation $\left(X^{2}(1)=7.04 ; p=0.008\right)$ (Table 3$)$, in the intervention group registering significantly less self-examination behaviors than in the control group. As a result of this finding for this variable, intra-group comparisons were made between the time of initial assessment and the time of final assessment by applying binomial tests. Thus, for the intervention group, a statistically significant increase was found from 27 to $63 \%$ of those who performed breast self-examination at the end of the program compared to those who performed breast self-examination in the previous month. Within the control group, the percentage increase of those who performed breast self-examination in the last month was statistically insignificant (from 45 to 54\%) (Table 4). These results show that there are significant differences between the percentage of women in the intervention and control group who reported breast self-examination after program completion, therefore the third hypothesis of the study is supported.

The increase in the percentage of women who examined their breasts in the last month from pretest to posttest was analyzed for the intervention group and in the subgroups consisting of participants who stated that they perform breast self-examination once a month, occasionally and never. Thus, it was found that a significant increase in this percentage took place in the subgroup of those who say

Table 3 Comparison of breast self-examination behavior between intervention group and control group at pretest and posttest

\begin{tabular}{clll}
\hline Variable & $\begin{array}{l}\text { Interven- } \\
\text { tion group } \\
(N=107) \\
\mathrm{N}(\%)\end{array}$ & $\begin{array}{l}\text { Control group } \\
(N=103)\end{array}$ & Statistics (chi square) \\
& & \\
\hline Pretest & & \\
BSE in the last month & & \\
No $78(72.9)$ & $57(55.3)$ & $\mathrm{X}^{2}(1)=7.04 ; p=0.008^{* *}$ \\
Yes $29(27.1)$ & $46(44.7)$ & \\
Posttest & & \\
BSE in the last month & & \\
No $\quad 40(37.4)$ & $47(45.6)$ & $\mathrm{X}^{2}(1)=1.47 ; p=0.22$ \\
Yes $\quad 67(62.6)$ & $56(54.4)$ & \\
\hline
\end{tabular}

$B S E$ breast seff-examination

${ }^{*} p<0.05 ;{ }^{* *} p<0.01$ 
Table 4 Changes in breast self-examination behavior in the intervention and control group between pretest and posttest

\begin{tabular}{ccll}
\hline Variable & $\begin{array}{l}\text { Pretest } \\
\mathrm{N}(\%)\end{array}$ & $\begin{array}{l}\text { Posttest } \\
\mathrm{N}(\%)\end{array}$ & $\begin{array}{l}\text { Statistics } \\
\text { (binomial } \\
\text { test) }\end{array}$ \\
\hline \multicolumn{2}{l}{$\begin{array}{l}\text { Intervention group }(N=107) \\
\text { BSE in the last month }\end{array}$} & & \\
No & $78(72.9)$ & $40(37)$ & $p=0.01^{*}$ \\
Yes & $29(27.1)$ & $67(63)$ & \\
Control group $(N=103)$ & & \\
BSE in the last month & & \\
No & $57(55.3)$ & $47(46)$ & \\
Yes & $46(44.7)$ & $56(54)$ & \\
\hline
\end{tabular}

$B S E$ Breast seff-examination

${ }^{*} p<0.05$

they do monthly self-examination of the breasts (from $2.9 \%$ to $31 \%$ ) and in the subgroup of those who say they occasionally do self-examination of the breasts (from $29.8 \%$ to $80 \%$ ).

\section{Discussion}

Unlike previous studies that aimed to improve self-examination behaviors of breasts through face-to-face interventions, the present study aimed to change beliefs and knowledge about breast cancer and its detection and increase in numbers for those who perform self-examination through a program delivered by email. It was found that after participating in this program, women had a significantly higher perception of the severity of the disease and the benefits of self-examination. Also, the number of participants who performed breast self-examination after participating in the program was significantly higher than those who previously performed breast self-examination.

One of the hypotheses in the study was to increase women's knowledge about breast cancer and its early detection. This hypothesis has not been confirmed, which can be explained by the previous high level of knowledge of the participants, which left little room for improvement. This situation can be understood if we remember that most of those who were included in the research are students, thus benefiting from high education and high exposure to information.

Another hypothesis of the research that was only partially confirmed was that by participating in this program, the beliefs of the participants associated with breast cancer and breast self-examination will be significantly modified. Thus, significant increases were obtained in the perception of the severity of the disease and the benefits of self-examination of the breasts, but not in susceptibility, cues to action, self-efficacy and no significant decrease in barriers. These changes are consistent with what has been achieved in other research. If in the study conducted by Hajian et al. (2011), as in the present study, only changes in the perception of disease severity and the benefits of breast self-examination were found, in other studies other significant changes were obtained such as those in the perception of susceptibility (Secginli \& Nahcivan, 2011), self-efficacy (Secginli \& Nahcivan, 2011; Akhtari-Zavare et al., 2016; Tuzcu et al., 2016) and barriers (AkhtariZavare et al., 2016). In the case of the present research, the average young age of the participants (23 years old), the good and very good health reported by most of them and the lack of a history of breast cancer in the family for most of them, can explain the fact that there were no significant changes in the susceptibility to develop this disease. According to Akhtari-Zavare et al. (2016) it is possible that practical demonstrations on how to perform self-examination of the breasts may contribute to increased self-efficacy, therefore the lack of such demonstrations in the current program may have contributed to the lack of changes in this component of HBM.

The literature shows that health education interventions are effective in changing beliefs and knowledge levels, but behavioral change is difficult. The most important change highlighted in this study refers to the increase in the percentage of women who, as a result of participation, performed breast self-examination. Thus, half of the women in the intervention group who did not perform the breast examination before the program, after participating, did so. The research results showed that the intervention delivered via email led to the targeted behavioral change, being consistent with what was obtained in the case of other programs based on HBM (Hajian et al., 2011; Secginli \& Nahcivan, 2011; Akhtari-Zavare et al., 2016; Tuzcu et al., 2016). However, we note that in the case of women who did not perform breast self-examination at all before the program, this behavioral change was not significant therefore further studies are needed to highlight the variables to be addressed to obtain significant changes in their case.

The intervention in this study was based on HBM, a model that over time has proven effective in its ability to generate behavioral changes that promote health. The novelty brought by this program refers to the implementation method. Unlike the interventions previously described in the literature, it was not face-to-face but used emails sent to participants for 30 days. This method of implementation had the advantage of allowing participation regardless of the geographical location of women as well as reducing the time costs of participants and researchers. Also, this research used a minimum of resources compared to previous studies in which a variety of educational methods were used (lecture, practical demonstration, watching movies). Such an implementation also allows participants to review the content of 
the program in the future. Especially in the case of countries where the financial resources of the health system are limited but where the coverage of the internet is high (as in the case of Romania) the development of such interventions can be a viable solution to promote early detection of breast cancer and decrease in mortality caused by this disease.

In addition to the advantages of this study such as experimental design with intervention group and control and random distribution of participants, it also has some limitations. An important limitation of the design refers to the fact that there were no subsequent evaluations that allow following the way in which the behavioral change obtained is preserved in time. In terms of the content of the program, it only aimed to increase the number of women who perform self-examination of the breasts without considering the correctness of behavior.

Future studies could include the application of similar programs to improve other early detection behaviors for breast cancer such as mammography or clinical examination. Such interventions could also include women at increased risk of developing the disease, such as firstdegree relatives of patients already diagnosed. In addition, this type of program can be adapted to promote prevention and early detection behaviors for other cancers. Another direction of research that future studies may address is the extension of the theoretical framework represented by HBM. One of the criticisms of this model is that it includes only individual factors regardless of the person's social context (Glanz \& Schwartz, 2008). Future studies may consider extending the HBM model by including interpersonal relationships and integrating new concepts such as group resilience (Pagliaro et al., 2013). Because there are studies that show the importance of matching the content of messages with the recipient's individual affective or cognitive orientation (Aquino et al., 2020), future research could focus on extending HBM to also consider the affective dimension.

\section{Conclusion}

The intervention based on HBM sent to the participants through emails was effective in terms of significantly increasing the number of those who performed self-examination of the breasts. The results obtained and the low costs involved may be arguments for its implementation by health care providers to promote the early detection of breast cancer.

Funding The authors declare that no funding has been received for the conduct of this study and/ or preparation of this manuscript.
Data Availability The data that support the findings of this study are available on the osf.io repository. This study was registered before implementation on the osf.io platform with https://doi.org/10.17605/ OSF.IO/JDX78

\section{Declarations}

Ethical Approval All procedures performed in studies involving human participants were in accordance with the ethical standards of the institutional and/or national research committee and with the 1964 Helsinki declaration and its later amendments or comparable ethical standards.

This research study has been approved by the Ethics Committee of the University of the West, Timișoara, Romania (decision no 6540/ 10.02.2021).

Informed Consent All participants expressed informed consent.

Competing Interests The authors declare that they have no conflict of interest.

\section{References}

Akhtari-Zavare, M., Juni, M. H., Said, S. M., Ismail, I. Z., Latiff, L. A., \& AtaollahiEshkoor, S. (2016). Result of randomized control trial to increase breast health awareness among young females in Malaysia. BMC Public Health, 16(1), 738. https://doi.org/10. 1186/s12889-016-3414-1.

American Cancer Society. (2021). Retrieved from https://www.cancer. org/content/dam/cancer-org/research/cancer-facts-and-statistics/ annual-cancer-facts-and-figures/2021/cancer-facts-and-figures2021.pdf.

Anderson, B. O., \& Jakesz, R. (2008). Breast cancer issues in developing countries: An overview of the breast health global initiative. World Journal of Surgery., 32(12), 2578-2585. https://doi.org/10. 1007/s00268-007-9454-z.

Anderson, B. O., Braun, S., Lim, S., Smith, R. A., Taplin, S., \& Thomas, D. B. (2003). Global Summit Early Detection Panel. Early detection of breast cancer in countries with limited resources. Breast Journal, 9(2), S51-9. https://doi.org/10.1046/j. 1524-4741.9.s2.4.x

Aquino, A., Alparone, F. R., Pagliaro, S., Haddock, G., Maio, G. R., Perrucci, M. G., \& Ebisch, S. J. H. (2020). Sense or sensibility? The neuro-functional basis of the structural matching effect in persuasion. Cognitive, Affective, \& Behavioral Neuroscience, 20(3), 536-550. https://doi.org/10.3758/s13415-020-00784-7.

Carelli, I., Pompei, L. M., Mattos, C. S., Ferreira, H. G., Pescuma, R., Fernandes, C. E., \& Peixoto, S. (2008). Knowledge, attitude and practice of breast self-examination in a female population of metropolitan São Paulo. The Breast., 17(3), 270-274. https://doi. org/10.1016/j.breast.2007.10.010.

Crossing, S., \& Manaszewicz, R. (2003). Breast self examination: Be alert but not alarmed? Medical Journal of Australia., 178(12), 646-647. https://doi.org/10.5694/j.1326-5377.2003.tb05395.x.

Dewi, T. K., Massar, K., Ruiter, R. A. C., \& Leonardi, T. (2019). Determinants of breast self-examination practice among women in Surabaya, Indonesia: An application of the health belief model. BMC Public Health, 19, 1581. https://doi.org/10.1186/ s12889-019-7951-2.

Didarloo, A., Nabilou, B., \& Khalkhali, H. R. (2017). Psychosocial predictors of breast self-examination behavior among female students: An application of the health belief model using logistic 
regression. BMC Public Health, 17(1), 861. https://doi.org/10. 1186/s12889-017-4880-9.

Furtunescu, F., Bohiltea, R. E., Voinea, S., Georgescu, T. A., Munteanu, O., Neacsu, A., \& Pop, C. S. (2021). Breast cancer mortality gaps in Romanian women compared to the EU after 10 years of accession: Is breast cancer screening a priority for action in Romania? (Review of the Statistics). Experimental and Therapeutic Medicine, 21, 268. https://doi.org/10.3892/etm.2021.9699.

Glanz, K., \& Schwartz, M. (2008). Stress, coping, and health behavior In Glanz, K., Rimmer, B.K., \& Viswanath, K. (Eds.) Health behavior and health education-theory, research and practice (pp.211-235), Wiley.

Hajian, S., Vakilian, K., Najabadi, K. M., Hosseini, J., \& Mirzaei, H. R. (2011). Effects of education based on the health belief model on screening behavior in high risk women for breast cancer, Tehran, Iran. Asian Pacific Journal of Cancer Prevention, 12(1), 49-54.

Heer, E., Harper, A., Escandor, N., Sung, H., McCormack, V., \& FidlerBenaoudia, M. M. (2020). Global burden and trends in premenopausal and postmenopausal breast cancer: A population-based study. The Lancet Global Health, 8(8), e1027-e1037. https://doi. org/10.1016/S2214-109X(20)30215-1.

Ju, N., Liao, S., Zheng, S., Hua, T., \& Zhang, S. (2021). Structural equation modeling to detect predictors of breast self-examination behavior: Implications for intervention planning. The Journal of Obstetrics and Gynaecology Research, 47(2), 583-591. https:// doi.org/10.1111/jog.14550.

Lechner, L., De Nooijer, J., \& De Vries, H. (2004). Breast self-examination: Longitudinal predictors of intention and subsequent behaviour. European Journal of Cancer Prevention, 13(5), 369-376. https://doi.org/10.1097/00008469-200410000-00003.

Luszczynska, A., \& Schwarzer, R. (2003). Planning and self-efficacy in the adoption and maintenance of breast self-examination: A longitudinal study on self-regulatory cognitions. Psychology \& Health, 18(1), 93-108. https://doi.org/10.1080/0887044021000019358.

Mason, T. E., \& White, K. M. (2008). Applying an Extended Model of the Theory of Planned Behaviour to Breast Self-examination. Journal of Health Psychology, 13(7), 946-955. https://doi.org/10. 1177/1359105308095069.

National Breast Cancer Foundation. (2021). Retrieved from https://www.nationalbreastc ancer.org/breast-cancer-sympt oms-and-signs.

National Cancer Institute. (2021). Retrieved from https://www.cancer. gov/types/breast/patient/breast-prevention-pdq.

Pagliaro, S., Alparone, F.R., Picconi, L., Paolini, D., \& Aquino, A. (2013). Group based resiliency: Contrasting the negative effects of threat to the in group. Current Research in Social Psychology. http://citeseerx.ist.psu.edu/viewdoc/summary?doi=10.1.1. 409.4964.

Rosenstock, I. M. (1974). Historical origins of the health belief model. Health Education Monographs., 2(4), 328-335.

Secginli, S., \& Nahcivan, N. O. (2011). The effectiveness of a nurse-delivered breast health promotion program on breast cancer screening behaviours in non-adherent Turkish women: A randomized controlled trial. International Journal of Nursing Studies, 48(1), 24-36. https://doi.org/10.1016/j.ijnurstu.2010.05. 016.

Ștefanuț, A.M, \& Vintilă, M. (2021). Psychometric properties of the Romanian version of Champion's Health Belief Model Scale for breast self-examination. Manuscript submitted for publication.

Ștefănut,, A. M., Vintilă, M., \& Sârbescu, P. (2020). Perception of disease, dyadic coping and the quality of life of oncology patients in the active treatment phase and their life partners: Study protocol of an approach based on the actor-partner interdependence model. European Journal of Cancer Care, e13497. https://doi. org/10.1111/ecc13374.

Swami, V., Tran, U. S., Barron, D., Afhami, R., Aimé, A., Almenara, C. A., et al. (2020). The breast size satisfaction survey (BSSS): Breast size dissatisfaction and its antecedants and outcomes in women from 40 nations. Body Image, 32, 199-217. https://doi. org/10.1016/j.bodyim.2020.01.006.

Thomas, D. B., Gao, D. L., Ray, R. M., Wang, W. W., Allison, C. J., Chen, et al. (2002). Randomized trial of breast self-examination in Shanghai: Final results. Journal of the National Cancer Institute, 94(19), 1445-1457. https://doi.org/10.1093/jnci/94.19.1445.

Tu, S. P., Reisch, L. M., Taplin, S. H., Kreuter, W., \& Elmore, J. G. (2006). Breast self-examination: Self-reported frequency, quality, and associated outcomes. Journal of Cancer Education, 21(3), 175-181. https://doi.org/10.1207/s15430154jce2103_18.

Tuzcu, A., Bahar, Z., \& Gözüm, S. (2016). Effects of interventions based on health behavior models on breast cancer screening behaviors of migrant women in Turkey. Cancer Nursing, 39(2), E40-E50. https://doi.org/10.1097/ncc.0000000000000268.

van Dooren, S., Rijnsburger, A. J., Seynaeve, C., Kriege, A., Duivenvoorden, H. J., Bartels, C. C., et al. (2003). Psychological distress and breast self-examination frequency in women at increased risk for hereditary or familial breast cancer. Community Genetics, 6(4), 235-241. https://doi.org/10.1159/000079385.

Vintilă, M., Ştefănuț, A. M., \& Sârbescu, P. (2019). Effectiveness of couple psycho-oncological interventions in increasing patients and their partners'adaptation to disease: A systematic review and a meta-analysis. Current Psychology, 6, 1-23. https://doi.org/10. 1007/s12144-019-00543-z.

World Health Organization. (2021a). retrieved from https://www.who. int/news-room/fact-sheets/detail/cancer.

World Health Organization. (2021b). retrieved from https://www.who. int/health-topics/cancer\#tab=tab_2.

World Health Organization. (2021c). retrieved from https://www.who. $\mathrm{int} /$ cancer/detection/breastcancer/en/.

World Health Organization. (2021d). retrieved from https://www.who. int/cancer/country-profiles/ROU_2020.pdf.

Publisher's Note Springer Nature remains neutral with regard to jurisdictional claims in published maps and institutional affiliations. 